\title{
ANALYSIS OF A MULTI-ECHELON PRODUCTION- INVENTORY SYSTEM WITH RANDOM SUPPLY*
}

\author{
Attila Chikán and Gyula Vastag \\ Karl Marx University of Economics, Budapest (Hungary)
}

\section{ABSTRACT}

In an earlier paper a multi-echelon production-inventory system has been described and a heuristic suggestion has been developed. The purpose of this paper is to give further analysis of the same system; namely, its dynamic behavior is discussed.

\section{THE SYSTEM}

A detailed description of the multi-echelon production-inventory system and its operation is given in ref. [1]. Here only the main features of the system are outlined.

The system is a somewhat simplified model of a real company with several fairly independent plants. These plants operate as separate profit centers, for which only the "rules of the game" are determined, and under these rules they make their own decisions. The production process includes a number of plants which are interconnected basically in a convergent way but with one divergent phase included. (The system can be seen in Fig. 1).

The plants receive the production task from the Master Production Schedule (MPS) which is based on market forecast for the end item of the company. The MPS is determined for a three month period - within that the plants schedule their production independently.

The company is strong in the market which means that it can dictate the delivery condi-

*Presented at the Fourth International Working Seminar on Production Economics, Igls, Austria, Feb. 17-21, 1986.

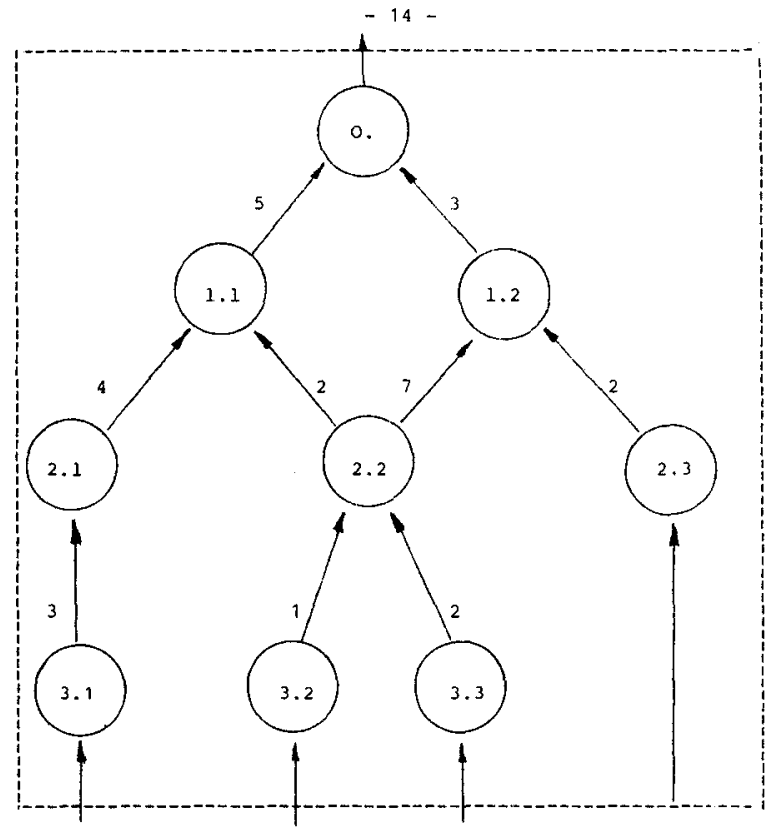

Fig. 1. The multi-echelon production-inventory system; structure of the plants and the unit requirements.

tions of its finished product. However the external supply of raw materials and spares of the company is subject to random factors and this fact influences the operation of the whole system. The independent production schedul- 
ing of the various plants and the random raw material supply together lead to the randomness of supply at each plant. Our task is to determine the production lot sizes and the safety stocks in the system so as to ensure the operation at minimal costs.

In the previous paper which we have referred to above, a heuristic solution has been suggested. This solution gave fairly good results for a static model, but couldn't handle the dynamic operation of the system. In this paper we deal with the dynamic version of our heuristics.

\section{THE OPERATION}

The company can forecast its demand with high reliability for about two years. The basic information for the operation of the system is the time series of demand (the long-range production plan) for two years.

The Master Production Schedule is determined for a three month period. (This means that the time horizon of the production plan is eight periods). Based on this MPS, an MRP procedure determines the net requirements for the various items in the system. (A one item-one plant correspondence is supposed, which seems acceptable in the real system as well as for our purposes.)

Each plant $j$ on echelon $i$ has a practically continuous production pattern, and determines its delivery schedule independently.

Given the net requirement for the finished product of each plant $i j$ (which in fact are semifinished from the point of view of the whole company) the following questions have to be answered:

(a) What should be the delivery lot sizes, or (which is obviously the same question) how many deliveries should be made during the scheduling period?

(b) How can it be achieved that the interest of the whole system is considered when preparing the plants own independent delivery plan?

(c) How can the various plants protect themselves against the uncertainty arising from the fact that although the lot size of their supplying plant is fixed, the delivery time is random in consequence of the uncertain character of the raw material input?

Various answers can be provided to these questions, with which the system can operate similarly well. The three basic approaches to similar multi-stage lot-sizing problems are described for example in ref. [2] as follows:

(i) The first approach focuses on algorithms which yield production schedules and order quantities for the entire product structure.

(ii) The Hierarchical Production Planning following the organizational lines links high-level aggregate planning with detailed operational planning.

(iii) The most common approach is to decompose the multi-level problem into a series of single-stage lot-sizing problems. In this case the levels are analyzed separately from each other - the BOM represents the only connection among them.

Based on principle (iii) we used the following approach to the questions:

(a) The lot sizes can be determined by some variant of the economic order quantity (EOQ model).

(b) The connection between the subsequent plants is made through the inventory between the two echelons. We assume that once an item is produced at a workshop on echelon $i$ it is kept in stock at this workshop until the production of the whole delivery lot is finished and then it is delivered to the input stocking point of a plant on the $(i-1)$ echelon. This procedure leads to the fact that the lot size of plant $i$ influences the input stock of plant $(i-1)$ and need to be considered when determining lot sizes. This leads to an, at least, partly common interest between plants $i$ and $(i-1)$.

(c) Since the delivery schedule of plant $i$ is to be considered random from the point of view of plant $(i-1)$, a safety stock must be held at 
the input stocking point of plant $(i-1)$ to ensure that its production schedule can be met (at least with a high probability).

A reliability type model is used to determine the safety stock needed in consequence of the random supply. This reliability model determines the initial stock at the beginning of the scheduling period needed to meet the demand with high probability considering the random character of supply (which in our case means the randomness of the arrival time of equal lots coming from the plant at the preceding level). Since this safety stock depends on the frequency of arrivals of the next period it must be revised before each period, well in advance. Since our assumption is that all order arrives within one scheduling period (only the arrival time is random ), this means that a decision on the initial stock of a period must be made one period earlier. This decision will of course influence the actual net requirement of the previous period, namely the requirement stemming from the MRP must be adjusted to achieve the target initial stock of the next period.

We do not handle the occurence of shortage. This means that we suppose that the safety stock is large enough to ensure a safe operation. Considering that, according to the assumptions, the total quantity ordered by the higher level arrive before the end of the period and only its time pattern is unknown, this assumption is satisfying from a practical viewpoint.

This procedure is a recursive one, i.e. we must know how much ending inventory is planned by the company for the end of the whole planning horizon. The procedure can be used for a rolling schedule, and also can handle the change of the parameters within the planning period.

\section{THE MODEL}

The following notations will be used: $r_{i j}^{t}$ demand (production quantity sched- uled) for the plant $i j$ in period $t$;

$n_{i j}^{t} \quad$ number of deliveries from plant $i j$ (the number of production lots; after finishing each lot delivery is performed);

$\beta_{i j} \quad$ the unit value of the product $i j$ (independent of $t$ );

$h_{i j} \quad$ the unit holding cost of the period $i j$ independent of $t$, and the location of the product (i.e. whether it is stored in a store of level $i$, the producer or level $(i-1)$, the user). In this version of the model it is assumed that $h_{i j}=0.3 \beta_{i j}$;

$w_{i j} \quad$ the constant cost of one delivery from plant $i j$, independent of $t$;

$m_{i} \quad$ the number of the products at level $i$;

$\delta$ the coefficient with which the safety stock of the $(T+1)$ th period is determined (originally it was 0.8 );

$T$ number of the periods in the time horizon of the production plan;

$1-\epsilon_{i j}^{t}$ safety factor, the probability of meeting all demand in the scheduling period. In this version it is assumed that $1-\epsilon_{i j}^{l}=1-\epsilon=0.99$ throughout the system;

$I_{i j}^{(s) t} \quad$ safety stock of the product of plant $i j$ in period $t$;

$I_{i j}^{(c) t} \quad$ cycle stock of the product of plant $i j$ in period $t$;

$I_{i j}^{(T) t} \quad$ total inventory, $I_{i j}^{(T) t}=I_{i j}^{(s) t}+I_{i j}^{(c) t}$

$C\left(n_{i j}^{t}\right)$ the total system cost associated with the number of deliveries $n_{i j}^{t}$ from plant $i j$ in period $t$. Part of this cost will actually occur at plant $i j$ and the other part (namely, the cost of holding safety stock) at the subsequent plant at level $(i-1)$.

Using these notations the general form of the cost function at plant $i j$ in period $t$ can be written as follows:

$$
\begin{aligned}
C\left(n_{i j}^{t}\right)=h_{i j} I_{i j}^{(c) t}\left(r_{i j}^{t}, n_{i j}^{t}\right)+ & w_{i j}\left(n_{i j}^{t}\right) \\
& +h_{i j} I_{i j}^{(s) t}\left(n_{i j}^{t}, r_{i j}, \epsilon\right)
\end{aligned}
$$

As it has already been mentioned, the EOQ formula is used to determine the lot size at each 
plant. The value of demand used in the formulas is determined as follows:

$r_{i j}^{*}=r_{i j}^{\prime}+I_{i j}^{(s)(t+1)}-I_{i j}^{(s)}$

where

$r_{i j}^{t} \quad$ the demand for the product of plant $i j$ determined by the MRP procedure;

$I_{i j}^{S(t)}$ the safety stock actually held in order to protect against the uncertainty stemming from the random delivery of plant $i j$. This stock is physically held at the plant $(\mathrm{s})$ of level $(i-1)$. It is expressed in units of plant $i j$.

The value of $r_{i j}^{*_{t}}$ is the corrected demand for the product, where the correction is made in order to adjust the safety stock level. The calculation of the EOQ at any plant is the following:

$q_{i j}^{* t}=\sqrt{\frac{2 w_{i j} r_{i j}^{*}}{h_{i j}}}$

For the calculation of the safety stock we also need the number of deliveries, which can be obtained by using the following formula:

$n_{i j}^{* t}=\sqrt{\frac{r_{i j}^{*} h_{i j}}{2 w_{i j}}}=\sqrt{r_{i j}^{*}} \sqrt{\frac{h_{i j}}{2 w_{i j}}}$

The safety stock can be determined by a formula based on a reliability equation expressing the condition that the probability of shortage do not exceed a given level (in our case $0.01 \%$ ). We use the following formula (for the derivation see ref. [3]).

$I_{i j}^{(s) t}=r_{i j}^{* t} \cdot \sqrt{\frac{1}{n_{i j}^{* t}} \cdot \frac{1}{2} \cdot \ln \frac{1}{\epsilon}}$

This formula is valid only if there is only one user of the product of plant $i j$. In our case this condition is met except plant 2.2. We handle the production of plant 2.2 as it is described in ref. [1] - the essence is that plant 2.2 delivers to both users at the same time and proportionates the quantity delivered to the overall demand of the two users. Then the plant can be handled the same way as any other.
The above formula, eqn. (5) can be written in the following form:

$I_{i j}^{(s) t}=\left(r_{i j}^{t}+I_{i j}^{(s)(t+1)}-I_{i j}^{(s) t}\right) \cdot \sqrt{\frac{1}{n_{i j}^{*}} \cdot z}$

where

$z=\sqrt{\frac{1}{2} \ln \frac{1}{\epsilon}}$ is a constant for all plants and periods.

It is easy to see that we can use formulas (4) and (6) to determine the operating parameters of the system. For that we need to know the time series of forecasted demand $\left(r_{i j}^{t}\right)$, the ending inventory, the cost parameters and the reliability level.

The description and the steps of the algorithm we applied are as follows:

Input data: $r_{i j}^{t}, h_{i j}, w_{i j}, m_{i}, \epsilon, \delta$

$\left(t=1,2, \ldots, T ; i=1,2,3 ; j=1,2, \ldots, m_{i}\right)$;

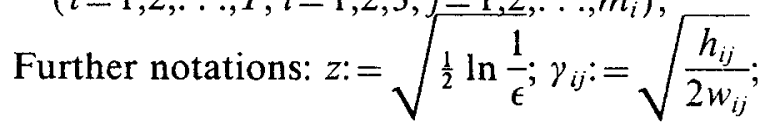

$I_{i j}^{(s)(T+1)}=: \delta \cdot r_{i j}^{T+1}$ for $\forall i$ and $\forall j$;

Step 1: For $t=T \alpha_{i j}:=r_{i j}^{i}+I_{i j}^{(s)(t+1)}$

$\left(i=1,2,3 ; j=1,2, \ldots, m_{i}\right)$

Step 2: Solve the following equation for $n_{i j}^{*_{i}}$

( $n_{i j}^{* t}$ is an integer variable)

$\left(n_{i j}^{*}\right)^{2}+z \cdot\left(n_{i j}^{*}\right)^{3 / 2}-\alpha_{i j}^{t} \cdot \gamma_{i j}^{2}=0$

(This equation is a transformation of eqns. (4) and (5)).

Step 3: Having solved the above equation, determine the value of $I_{i j}^{(s) t}$ :

Step 4: $r_{i j}^{* t}:=\alpha_{i j}^{t}-I_{i j}^{(s)}$

Step 5: If $t$ equals to 1 then Stop, else decrease $t$ by one and GO TO Step 1 .

\section{COMPUTATIONAL RESULTS}

We have made a lot of calculations to test our algorithm. A model based on the "Multi- 
TABLE I

Sample calculation testing the algorithm

\begin{tabular}{|c|c|c|c|c|c|c|c|c|c|c|c|c|c|c|c|}
\hline & Periods & 1 & 2 & 3 & 4 & 5 & 6 & 7 & 8 & 9 & Aver. & St. Dev. & Cost & & \\
\hline \multirow[t]{5}{*}{ Prod. 0} & Reqs. & 113 & 92 & 280 & 203 & 322 & 88 & 313 & 128 & 301 & 204 & 100 & Prod. 0 & & \\
\hline & Corr. reqs. & 113 & 92 & 280 & 203 & 322 & 88 & $3 ! 3$ & 128 & & 192 & 100 & & & \\
\hline & Del. numb. & 10 & 9 & 16 & 14 & 17 & 9 & 17 & 11 & & 12 & 3 & 800 & Set up & 960 \\
\hline & Lot size & 11 & 10 & 18 & 15 & 19 & 10 & 18 & 12 & & 14 & 3 & & & \\
\hline & C. stock & 5.5 & 5 & 9 & 7.5 & 9.5 & 5 & 9 & 6 & & 7 & 1 & 1422 & Hold. & 133842 \\
\hline safety & Prod. 1.1 & 307 & 350 & 581 & 507 & 600 & 359 & 630 & 562 & 1204 & 566 & 267 & & & \\
\hline stock & Prod. 1.2 & 171 & 188 & 322 & 277 & 327 & 194 & 354 & 319 & 722 & 319 & 165 & & Total & 143442 \\
\hline \multirow[t]{5}{*}{ Prod. 1.1} & Reqs. & 565 & 460 & 1400 & 1015 & 1610 & 440 & 1565 & 640 & 1505 & 1022 & 503 & Prod. 1.! & & \\
\hline & Corr. reqs. & 608 & 691 & 1326 & 1108 & 1369 & 711 & 1497 & 1282 & & 1074 & 352 & & & \\
\hline & Del. numb. & 9 & 9 & 12 & 11 & 12 & 9 & 13 & 12 & & 10 & 1 & 400 & Set up & 4000 \\
\hline & Lot size & 67 & 76 & 110 & 100 & $\begin{array}{r}114 \\
1 \quad 79\end{array}$ & 115 & 106 & & 95 & 18 & & & & \\
\hline & C. stock & 33.5 & 38 & 55 & 50 & 57 & 39.5 & 57.5 & 53 & & 47 & 9 & 87 & Hold. & 58278 \\
\hline safety & Prod. 2.1 & 1304 & 1474 & 2382 & 1988 & 2275 & 809 & 2612 & 2315 & 4816 & 2219 & 1138 & & & \\
\hline slock & Prod. 2.2 & 435 & 467 & 804 & 693 & 834 & 502 & 959 & 1220 & 7464 & 1486 & 2255 & & Total & 62278 \\
\hline \multirow[t]{5}{*}{ Prod. 2.1} & Reqs. & 2260 & 1840 & 5600 & 4060 & 6440 & 1760 & 6260 & 2560 & 6020 & 4088 & 2013 & Prod. 2.1 & & \\
\hline & Corr. regs. & 2430 & 2748 & $\$ 206$ & 4347 & 4974 & 3563 & 5963 & 5061 & & 4286 & 1257 & & & \\
\hline & Del. numb & 8 & 8 & 11 & 11 & 11 & 6 & 12 & 11 & & 9 & 2 & 100 & Set & 900 \\
\hline & Lot size & 303 & 343 & 473 & 395 & 452 & 593 & 496 & 460 & & 439 & 91 & & & \\
\hline & C. stock & 151.5 & 171.5 & 236.5 & 197.5 & 226 & 296.5 & 248 & 230 & & 219 & 45 & 5 & Hold. & 14661 \\
\hline ss & Prod. 3.1 & 3830 & 4189 & 6951 & 6021 & 7000 & 4313 & 7559 & 6740 & 14448 & 6783 & 3193 & & Total & 15561 \\
\hline \multirow[t]{5}{*}{ Prod. 3.1} & Reqs. & 6780 & 5520 & 16800 & 12180 & 19320 & 5280 & 18780 & 7680 & 18060 & 12266 & 6039 & Prod. 3.1 & & \\
\hline & Corr. reqs. & 7139 & 8282 & 15870 & 13159 & 16633 & 8526 & 17961 & 15388 & & 12869 & 4280 & & & \\
\hline & Del. numb. & 8 & 9 & 12 & 11 & 13 & 9 & 13 & 12 & & 10 & 1 & 100 & Set up & 1000 \\
\hline & Lot size & 892 & 920 & 1322 & 1196 & 1279 & 947 & 1381 & 1282 & & 1152 & 199 & & & \\
\hline & C. stock & 446 & 460 & 661 & 598 & 639.5 & 473.5 & 690.5 & 641 & & 576 & 99 & & Hold. & 11590 \\
\hline בנ ב & Prod. 3.1 & 2895 & 3359 & 6436 & 5337 & 6746 & 3458 & 7284 & 6241 & & 5219 & 1736 & & Total & 12590 \\
\hline \multirow[t]{5}{*}{ Prod. 1.2} & Reqs. & 339 & 276 & 840 & 609 & 966 & 264 & 939 & 384 & 903 & 613 & 301 & Prod. 1.2 & & \\
\hline & Corr. reqs. & 356 & 410 & 795 & 659 & 833 & 424 & 904 & 787 & & 646 & 218 & & & \\
\hline & Del. numb. & 10 & 11 & 14 & 13 & 15 & 11 & 15 & 14 & & 12 & 1 & 450 & Set up & 5400 \\
\hline & Lot size & 35 & 37 & 56 & 50 & 55 & 38 & 60 & 56 & & 48 & 10 & & & \\
\hline & C. stock & 17.5 & 18.5 & 28 & 25 & 27.5 & 19 & 30 & 28 & & 24 & 5 & 234 & Hold. & 88809 \\
\hline safety & Prod. 2.2 & 1087 & 1167 & 2009 & 1734 & 2086 & 1254 & 2399 & 3050 & 7464 & 2472 & 1977 & & & \\
\hline stocks & Prod. 2.3 & 448 & 494 & 804 & 713 & 823 & 517 & 890 & 772 & 1444 & 767 & 299 & & Total & 94209 \\
\hline \multirow[t]{5}{*}{ Prod. 2.2} & Reqs. & 3503 & 2852 & 8680 & 6293 & 9982 & 2728 & 9703 & 3968 & 9331 & 6337 & 3120 & Frod. 2.2 & & \\
\hline & Corr. reqs. & 3615 & 4031 & 8294 & 6786 & 8818 & 4330 & 10615 & 14626 & & 7639 & 3786 & & & \\
\hline & Del. numb. & 13 & 14 & 20 & 18 & 21 & 14 & 23 & 27 & & 18 & 4 & 300 & Set up & 5400 \\
\hline & Lot size & 178 & 287 & 414 & 377 & 419 & 309 & $46 !$ & 541 & & 385 & 91 & & & \\
\hline & C. stock & 139 & 143.5 & 207 & 188.5 & 209.5 & 154.5 & 230.5 & 270.5 & & 192 & 45 & 29 & Hold. & 78090 \\
\hline safety & Prod. 3.2 & 1786 & 2005 & 3330 & 2863 & 3374 & 2005 & 3660 & 3298 & 7464 & 3309 & 1707 & & & \\
\hline stock & Prod. 3.3 & 3043 & 3268 & 5624 & 4843 & 5799 & 3343 & 6133 & 5689 & 14929 & 5852 & 3613 & & Total & 83490 \\
\hline \multirow[t]{5}{*}{ Prod. 3.2} & Reqs. & 3503 & 2852 & 8680 & 6293 & 9982 & 2728 & 970 & 3968 & 9931 & 6337 & 3120 & Prod. 3.2 & & \\
\hline & Corr. $\mathrm{r}$ & 3722 & 4177 & 8213 & 6804 & 8613 & 4384 & 9341 & 8134 & & 6673 & 2254 & & & \\
\hline & Del. numb & 10 & 10 & 14 & 13 & 15 & 11 & 15 & 14 & & 12 & 2 & 120 & Set up & 1440 \\
\hline & Lot size & 372 & 417 & 586 & 523 & 574 & 398 & 622 & 581 & & 509 & 98 & & & \\
\hline & C. stock & 186 & 208.5 & 293 & 261.5 & 287 & 199 & 311 & 290.5 & & 254 & 49 & & Hold. & 17754 \\
\hline ss & Prod. 3.2 & 1509 & 1693 & 3330 & 2759 & 3492 & 1777 & 3787 & 3298 & & 2705 & 914 & & Total & 19194 \\
\hline \multirow[t]{5}{*}{ Prod. 3.3} & Reqs. & 7006 & 5704 & 17360 & 12586 & 19964 & 5456 & 19406 & 7936 & 180662 & 12675 & 6240 & Prod. 3.3 & & \\
\hline & Corr. reqs. & 7231 & 8060 & 16579 & 3542 & 7508 & 246 & 962 & 17176 & & 413 & 4859 & & & \\
\hline & Del. numb. & 13 & 14 & 20 & 18 & 21 & 14 & 22 & 21 & & 17 & 3 & 200 & Set up & 3400 \\
\hline & Lot size & 556 & 575 & 828 & 752 & 833 & 589 & 861. & 817 & & 726 & 130 & & & \\
\hline & C. stock & 278 & 287.5 & 414 & 376 & 416.5 & 294.5 & 430.5 & 408.5 & & 363 & 65 & & Hold. & 52209 \\
\hline ss & Prod. 3.3 & 2932 & 3268 & 6722 & 5491 & 7099 & 3343 & 7689 & 6964 & & 5438 & 1970 & & Total & 55609 \\
\hline \multirow[t]{5}{*}{ Prod. 2.3} & 678 & 552 & 1680 & 1218 & 1932 & 528 & 1878 & 768 & 1806 & 1226 & 603 & & Prod. 2.3 & & \\
\hline & Corr. reqs. & 724 & 862 & 1589 & 1328 & 1626 & 901 & 1760 & 1440 & & 1278 & 396 & & & \\
\hline & Del. numb. & 6 & 7 & 9 & 8 & 9 & 7 & 9 & 8 & & 7 & 1 & 150 & Set up & 1058 \\
\hline & Lot size & 120 & 123 & 176 & 166 & 180 & 128 & 195 & 180 & & 158 & 29 & & & \\
\hline & C. stock & 60 & 61.5 & 88 & 83 & 90 & 64 & 97.5 & 90 & & 79 & 14 & & 5 Hold. & 8955 \\
\hline \multirow[t]{2}{*}{ ss } & Prod. 2.3 & 293 & 349 & 644 & 538 & 659 & 365 & 713 & 583 & & 518 & 160 & & Total & 10005 \\
\hline & & & & & & & & & & & & & & Toral & 519868 \\
\hline
\end{tabular}


TABLE 2

Sensitivity of total cost to changes of various model parameters

\begin{tabular}{lllllll}
\hline $\begin{array}{l}\text { Demand } \\
\text { parameters }\end{array}$ & $\begin{array}{l}\text { Increase of delivery cost } \\
\mathrm{A}=\frac{w_{i j}^{\prime}}{\text { sij }}\end{array}$ & $\delta \mathrm{l}=0$ & $\delta 2=1 / 3$ & $\delta 3=2 / 3$ & $\delta 4=.8$ & $\delta 5=1.0$ \\
\hline $\mathrm{D} 1$ & $\mathrm{~A} 1=1$ & 308786 & 352295 & 398015 & 406236 & 430073 \\
$(137,47)$ & $\mathrm{A} 2=1 / 2$ & 368894 & 415049 & 457718 & 472066 & 496290 \\
& $\mathrm{~A} 3=1 / 3$ & 442091 & 457181 & 499972 & 516903 & 543807 \\
$\mathrm{D} 2$ & $\mathrm{~A} 1=1$ & 371268 & 410370 & 451609 & 470932 & 490177 \\
$(174,73)$ & $\mathrm{A} 2=1 / 2$ & 443267 & 480235 & 529856 & 533422 & 570446 \\
& $\mathrm{~A} 3=1 / 3$ & 494725 & 543470 & 578850 & 595488 & 622038 \\
$\mathrm{D} 3$ & $\mathrm{~A} 1=1$ & 385613 & 473634 & 550500 & 579868 & 629276 \\
$(195,96)$ & $\mathrm{A} 2=1 / 2$ & 477156 & 553991 & 631061 & 664667 & 729269 \\
& $\mathrm{~A} 3=1 / 3$ & 503244 & 599928 & 684915 & 715699 & 749803 \\
\hline
\end{tabular}

plan" spreadsheet program has been built to evaluate how the algorithm works.

The calculations show that the heuristic works, since it has given empirically meaningful results, and the computations carried out with different parameters provided acceptable and explainable changes in the cost structure. As for as operational variables of the system, we have found the following:

(1) The lot sizes are rather stable quantities, their standard deviations are relatively low. This allows for a stable production schedule and good capacity utilization.

(2) The safety stocks fluctuate with the demand almost proportionally. (This consequence can be expected because of the model applied.) In most cases the safety stock shows a somewhat smaller fluctuation, due to absorption of some of the demand fluctuation by changes in the lot size.

To analyse the effects of the changes in the various parameters of the system, the following computations have been carried out.

We have used three different uniformly distributed demand samples with the following means and standard deviations: $D 1=(137$, $47) ; \mathrm{D} 2=(174,73) ; \mathrm{D} 3=(195,96)$.

Three variations of the cost parameters have been considered: we decreased the original ratio of the holding and set-up costs to its half and third by multiplying the set-up cost by two and three. These variations, in the decreasing value of the ratio, are denoted by $\mathrm{A} 1, \mathrm{~A} 2, \mathrm{~A} 3$.

As it is described in the model, we have to estimate the safety stock of the last period. This safety stock will be given in percentage $(\delta)$ of the demand in the last period: $\delta 1=0 ; \delta 2=1 / 3$; $\delta 3=2 / 3 ; \delta 4=0.8 ; \delta 5=1.0$.

Such for example Table 1 shows the results of using the values of D3, A 1 and $\delta 4$. In this case the total cost of the operation of the system is $579,868 \mathrm{Ft}$.

Having made all the computations we have $3 \times 3 \times 5=45$ tables showing the results of the different demand patterns, cost parameters and estimations. A summary of the results is shown in Table 2.

The results show that the system works as can be expected.

(a) If the demand is increasing the total cost is also increasing.

(b) Having increased the set-up cost (decreased the ratio of the holding and set-up cost parameter), the total cost is increasing.

(c) A higher safety stock of the last period increases the total cost of the operation.

(d) The joint effect of simultaneous changes in more than one of the parameters has also been examined. There were no surprising results, in fact, both the opera- 
tional variables and the cost behave as expected.

\section{SUMMARY AND CONCLUSION}

The combination of two elementary models have been used to describe the operation of a realistic multi-stage production-inventory system of partially independent plants. A simple heuristics was used to determine the system's operational variables, namely the lot sizes and the safety stocks. The computations provided well explanable results. The conclusion is that in the case examined, as in many other cases as well, heuristical application of simple decision rules lead to well operationable system parameters.

\section{REFERENCES}

1 Chikán, A. (1985). Heuristic modelling of a multi-echelon production-inventory system. Engineering Costs and Production Economics. 9(1-3): 165-168.

2 Melnyk, S.A. and Piper, C.J. (1985). Leadtime errors in MRP: the lot-sizing effect. Int. J. Prod. Res., 23(2): 253-264.

3 Prékopa, A. (1981). Reliability type inventory models: A survey. In: A. Chikán (ed.). The Economics and Management of Inventories. Vol. 2. Elsevier, Amsterdam, pp. $477-490$. 